\title{
OBSERVING THE NEUTRON COMPONENT DURING THUNDERSTORM ACTIVITY AT A MOUNTAIN CR STATION
}

\author{
A.A. Lukovnikova \\ Institute of Solar-Terrestrial Physics SB RAS, \\ Irkutsk, Russia,luk@iszf.irk.ru \\ V.M. Aleshkov \\ Institute of Solar-Terrestrial Physics SB RAS, \\ Irkutsk,Russia,vic@iszf.irk.ru
}

\author{
A.S. Lysak \\ Institute of Solar-Terrestrial Physics SB RAS, \\ Irkutsk,Russia,axel@iszf.irk.ru
}

\begin{abstract}
During three summer months in 2015, the Cosmic Ray (CR) station Irkutsk-3000, located at 3000 $\mathrm{m}$ above sea level, measured the CR neutron component intensity with the 6NM64 neutron monitor, as well as the atmospheric electric field strength and the level of electromagnetic interference during lightning discharges. It is shown that the level of electromagnetic interfer-
\end{abstract}

ence, when registered during lightning discharges, depends considerably on the fixed level of signal discrimination. During observations, we observed no effects of thunderstorm discharges at the neutron monitor count rate at the CR station Irkutsk-3000.

Keywords: cosmic rays, atmospheric electricity.

\section{INTRODUCTION}

A statistically significant increase in the neutron detector count rate during periods of thunderstorm activity in the course of the three-year experiment at an altitude of $2743 \mathrm{~m}$ was first reported by Shah et al. [1985]. In this experiment, neutrons were detected by counters with $\mathrm{BF}_{3}$, surrounded by a polyethylene layer as a moderator. Changes in the electric field associated with lightning discharges were recorded using a linear antenna. Enoto et al. [2017] have shown that during a lightning discharge the bremsstrahlung radiation of relativistic electrons can initiate photonuclear reactions that produce neutrons. The possibility of generating neutrons produced by a lightning discharge is also discussed by Babich et al. [2013]. The authors attribute the enhancement of the neutron flux in thunderclouds and during thunderstorms to photonuclear reactions due to the bremsstrahlung radiation of avalanches of runaway high-energy electrons arising in a thunderstorm electric field. Babich et al. [2013] note that an increase in the neutron detector count rate in the thunderstorm atmosphere can be caused by any penetrating radiation generated in the atmosphere. At the same time, there are studies in which such neutrons were not detected [Alekseenko et al., 2015; Makhmutov et al., 2017; Chilingaryan, 2017].

Recently, experiments have been conducted to measure the neutron intensity during periods of thunderstorm activity. These studies were carried out at the Tien Shan mountain cosmic-ray station (3340 m altitude) with a complex Thunderstorm in 2004-2005 [Antonova et al., 2008]. The neutron component was recorded with the standard neutron monitor 18NM64 (the count rate of order of $5 \cdot 10^{6}$ pulse/hr).

Near Yakutsk in the Tuymaada valley, Starodubtsev et al. [2012] have examined short-term neutron bursts during thunderstorms, using a synchronized complex of instruments with different time resolution, the main of which was the neutron monitor 24NM64 (105 m altitude). They used 1-min resolution data corrected for pressure. The study of the dependence of the neutron monitor count rate on the atmospheric surface electric field strength during lightning discharges has shown that short-term neutron bursts are recorded when the threshold electric field strength on average exceeds $-16 \mathrm{kV} \cdot \mathrm{m}^{-1}$, the burst amplitude increasing with field strength.

During the experiment in the Tuymaada valley, statistically significant neutron bursts were observed in 9 powerful thunderstorms of 39 events.

The authors associate the results obtained in these experiments with the additional neutron flux produced by lightning discharges.

Authors of the studies that describe experiments conducted at the cosmic-ray (CR) stations located in the permafrost zone and in high mountains do not discuss mechanisms of neutron production in lightning discharges and their propagation in the atmosphere. It is doubtful whether the authors postulate a possible multiple enhancement of the neutron flux in lightning discharges and their propagation to the observation point. For example, in the experiment in the Tuymaada valley, the distance between the point of lightning stroke to the hill summit and the site of CR detection was $\sim 7 \mathrm{~km}$, i.e. 2-3 neutron free paths. It should be appreciated that the neutron monitor that detects the $\mathrm{CR}$ neutron component has a very narrow antenna pattern $\left(\sim \cos ^{6}(\theta)\right)$. Therefore, we think that the neutrons produced outside an observation point cannot make a significant contribution to the neutron monitor count rate.

We have carried out an experiment on recording the CR neutron component intensity at an altitude of $3000 \mathrm{~m}$ during thunderstorm activity.

In this paper, we present the results of simultaneous measurements of neutron count rates by the neutron monitor, atmospheric electric field, and electromagnetic interference during lightning discharges at the mountain CR station Irkutsk-3000 (at $3000 \mathrm{~m}$ ). 


\section{DATA AND EQUIPMENT}

The analysis is based on 1-min CR intensity data corrected for pressure, which have been obtained by the neutron monitor 6NM64 installed at an altitude of $3000 \mathrm{~m}$ The 6 NM64 count rate is $\sim 25 \cdot 10^{3}$ pulse/min, the statistical accuracy of the 1-min data is $\sim 0.7 \%$; of one counter, $\sim 1.4 \%$. The neutron component intensity is recorded using PCI-1780 recorders. The amplifierdiscriminator consists of two components: a linear amplifier with a current input operating in the currentvoltage conversion mode, and a threshold device with different levels of discrimination (at the level 0.4 0.5 V). The amplifier-discriminator input is connected to a twometer wire of the counter. This wire serves as an antenna for receiving electromagnetic emission of a thunderstorm if the counter body performing the role of the screen (for the antenna) is poorly grounded (when the station ground resistance is great). The CR station uses a connection diagram with a grounded cathode (high voltage is applied to the wire, the body is grounded) and with signal transmission to the amplifier through a highvoltage blocking capacitor.

As an electromagnetic interference (EMI) receiver we utilize the counter SNM-15 with gas removed and with electric power supply voltage. The method of detecting electromagnetic interference with an "empty" counter was first experimentally tested at the CR station Irkutsk3000 in the 1980s [Kozlov, Yanchukovsky, 1987; Yanchukovsky, Kozlov, 1988]. EMI signals with different levels of discrimination (discrimination threshold 1 is set at a level of $0 \mathrm{~V}$; threshold discrimination 2 , at $0.2 \mathrm{~V}$ ) are calculated in individual channels of the recorder. The thresholds were selected according to discriminatory curves of the neutron counter [Kozlov, Yanchukovsky, 1987].

The atmospheric electric field strength was measured using an electrostatic fluxmeter designed and manufactured in the design office of the ISTP SB RAS research-and-development shop [Aleshkov, Molodykh, 2012]. It has the following characteristics:

- measurement range is from -30000 to $+30000 \mathrm{~V}$;

- accuracy is $\pm 50 \mathrm{~V}$;

- shielding plate revolution is $3000 \mathrm{rev} / \mathrm{min}$.

The amplifier operated in the differential measurement mode to avoid electromagnetic interference; the phase detector was made using an optocoupler to determine the potential gradient sign. We processed 1-s data.

\section{RESULTS AND CONCLUSIONS}

Figures 1-4 plot neutron count rates $(a)$ and electromagnetic interference $(b, c)$ recorded by an amplifier with different discrimination thresholds $(0.2 \mathrm{~V}$ and $0 \mathrm{~V})$, as well as electric field strength for June 14, 15, 22, 25, $2015(d)$.

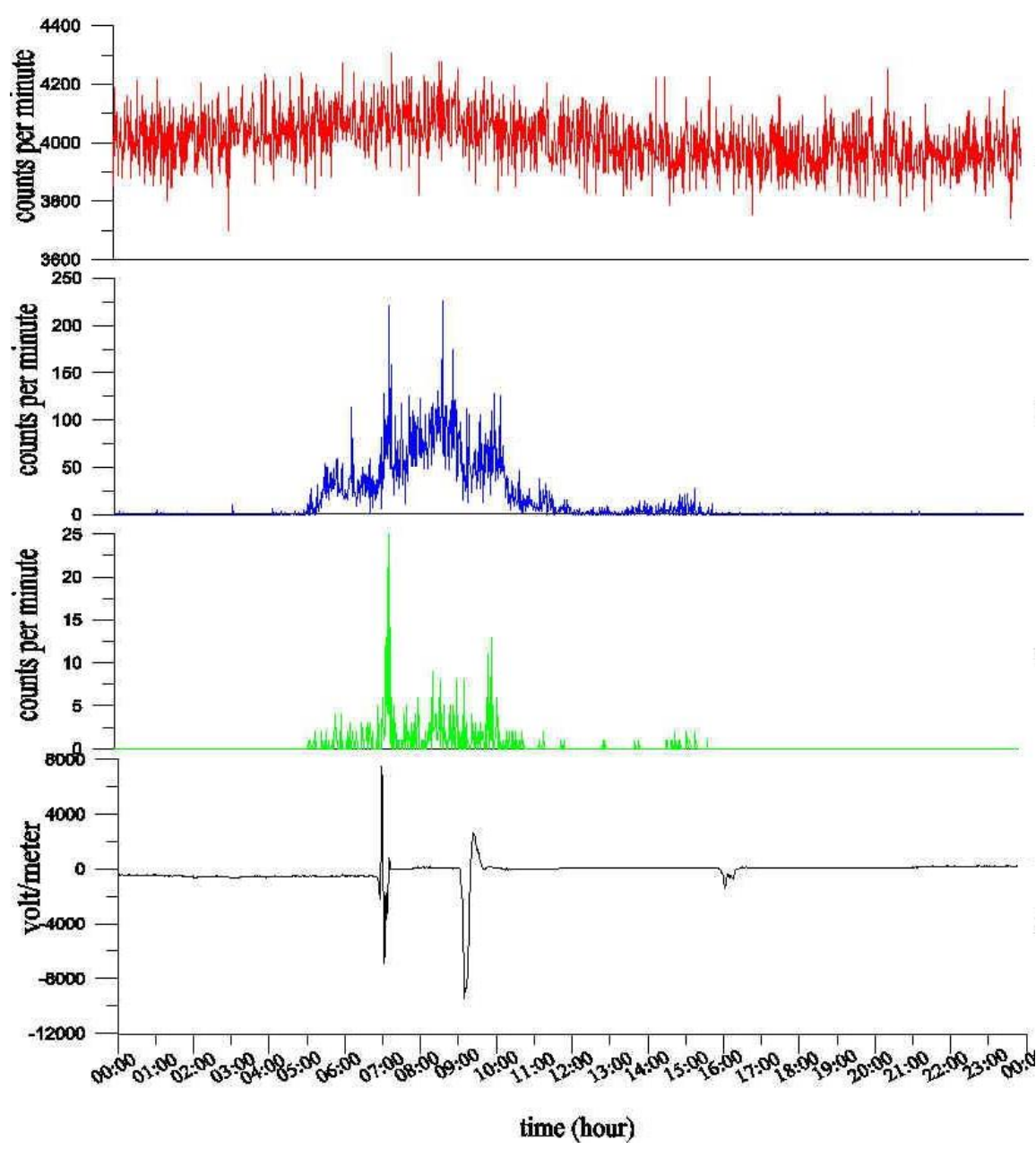

Figure 1. Neutron count rates $(a)$ and electromagnetic interference level when recorded with different discrimination thresholds of amplifiers $0.2 \mathrm{~V}(b)$ and $0 \mathrm{~V}(c)$ respectively; electric field strength according to data from the fluxmeter installed in the CR station Irkutsk-3000 (d) for June 14, 2015 


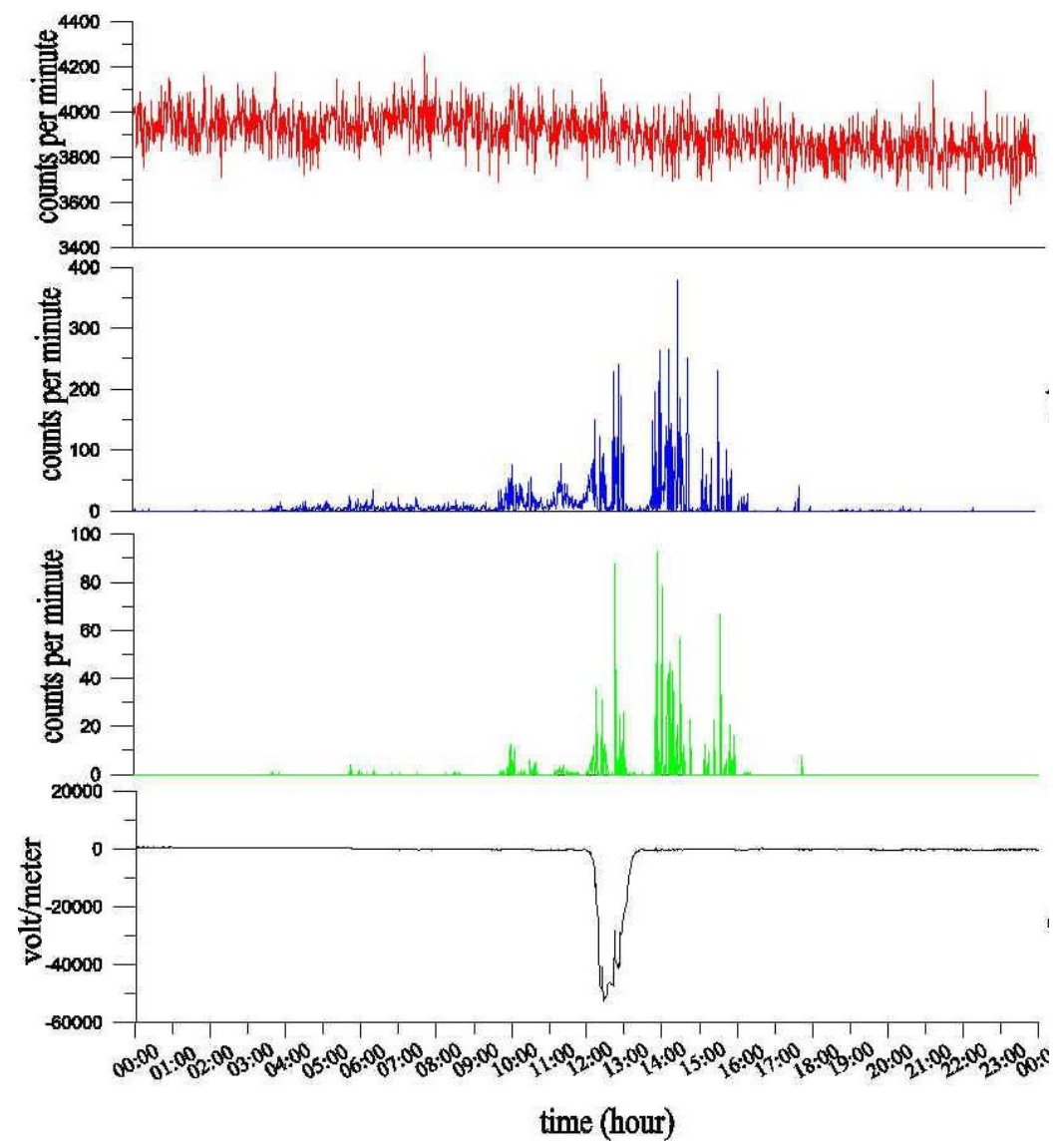

Figure 2. The same as in Figure 1 for June 15, 2015

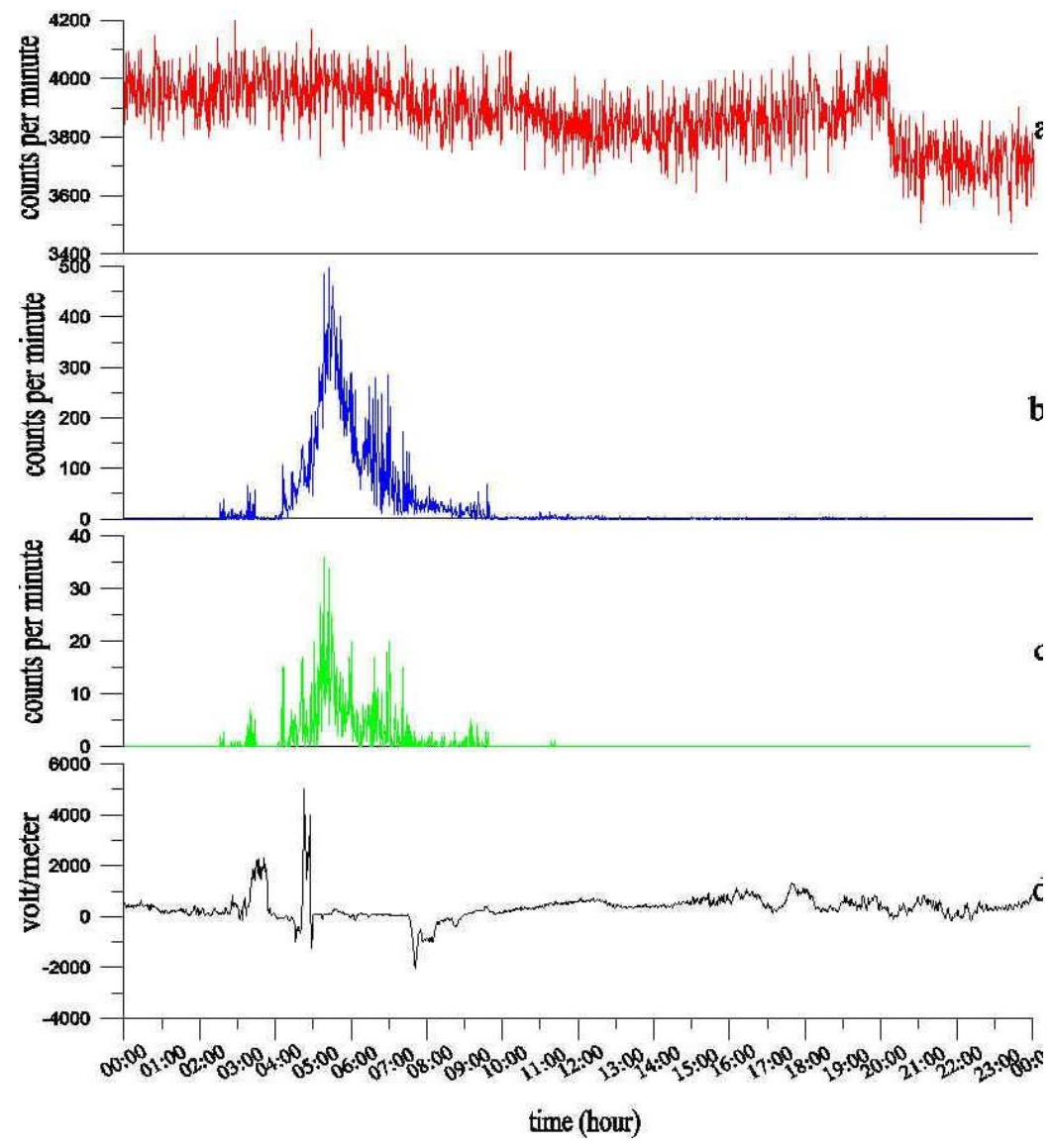

Figure 3. Neutron count rates $(a)$ and electromagnetic interference level when recorded with different discrimination thresholds of amplifiers $0.2 \mathrm{~V}(b)$ and $0 \mathrm{~V}(c)$ respectively; electric field strength according to data from the fluxmeter installed in the CR station Irkutsk-3000 (d) for June 22, 2015 


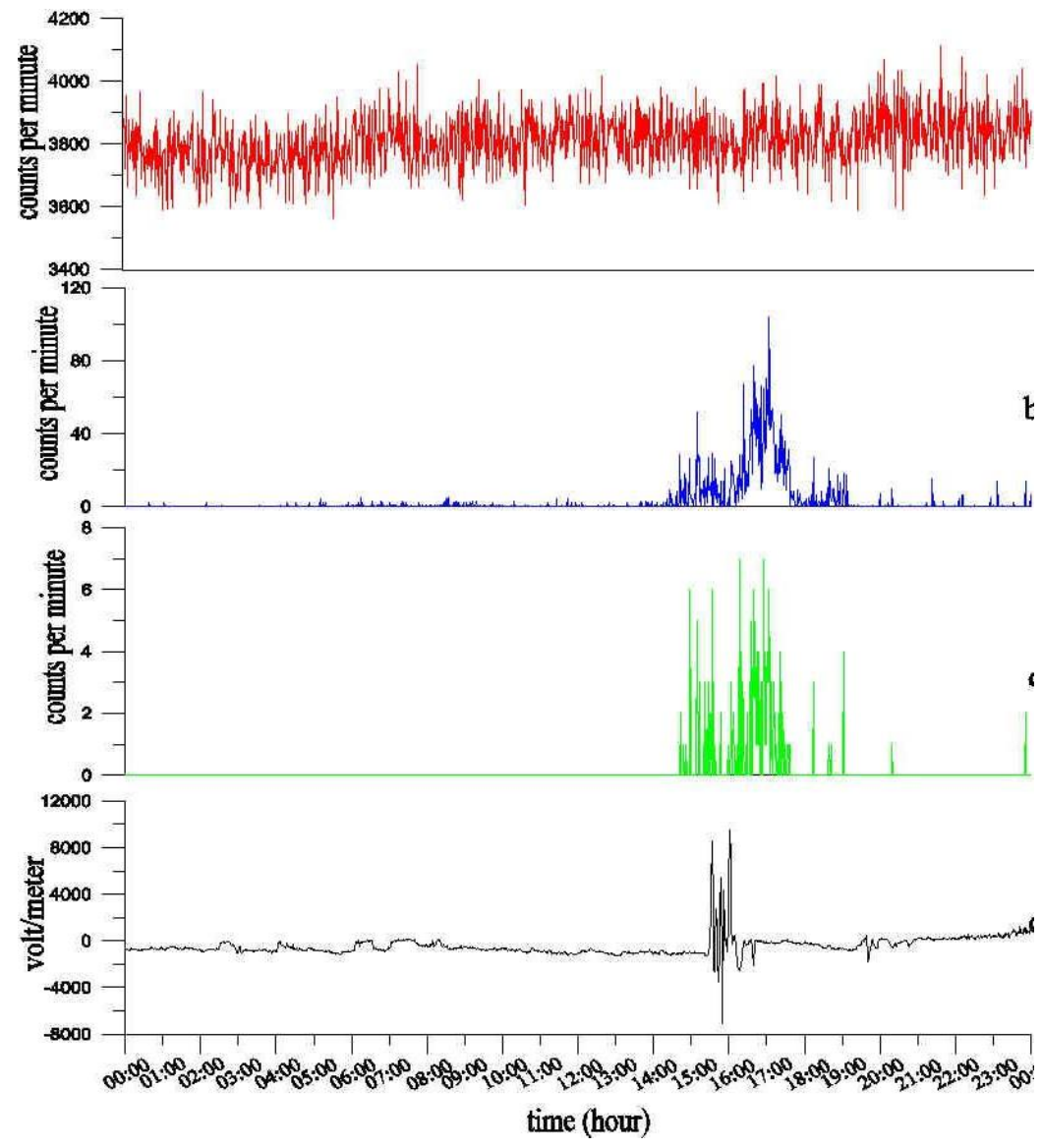

Figure 4. The same as in Figure 3 for June 25, 2015

The level of electromagnetic interference when recorded during lightning discharges is shown to depend largely on a fixed level of signal discrimination. Thus, the number of electromagnetic interference recorded at the discrimination level of $0.2 \mathrm{~V}$ is smaller 5-10 times than that at $0 \mathrm{~V}$, and the number of interference at $0.2 \mathrm{~V}$ in all the above lightning events does not exceed the statistical error in identifying useful information.

When analyzing data on the neutron monitor count rate at the CR station Irkutsk-3000 at a $0.4 \mathrm{~V}$ discrimination level chosen for regular measurements within the statistical accuracy, we observed no increases in the count rate during lightning discharges.

The short-term increases in the number of pulses recorded during lightning discharges [Shah et al., 1985; Antonova et al., 2008; Starodubtsev et al., 2012] must have been caused by the contribution of electromagnetic interference to the neutron count rate of monitors. To ensure protection from EMI requires us to improve the interference resistance of CR stations and follow requirements for ground connection. Our study has shown that EMI occurring during thunderstorms had no effect on recording equipment of the CR station Irkutsk-3000. We have observed that the neutron monitor is made so that it cannot detect the neutrons that appear far from the place of their detection, as well as particles from surrounding objects. We do not know the mechanism of acceleration of nucleons to relativistic energies in thunderstorm electric fields so that they can have 2-3 free paths and produce neutrons that can reach the point of their recording.
The work was performed with budgetary funding of Basic Research program II.16. The results were obtained using the equipment of Center for Common Use «Angara» [http://ckp-rf.ru/ckp/3056] and the Unique Research Facility Russian National Ground Network of Cosmic Ray Stations (CRS Network).

We thank Sdobnov V.E., a leading researcher of ISTP SB RAS, for helpful advice and discussion.

\section{REFERENCES}

Alekseenko V., Arneodo F., Bruno G., Giovanni A.Di., Fulgione W., Gromushkin D., Shchegolev O., Stenkin Yu., Stepanov V., Sulakov V., Yashin I. Decrease of atmospheric neutron counts observed during thunderstorms. Phys. Rev. Lett. 2015, vol. 114, 125003. DOI: 10.1103/PhysRevLett.114.125003.

Aleshkov V.M., Molodykh S.I. Equipment for measuring atmospheric electricity parameters. Seysmoionosfernye $i$ seismoelektromagnitnye protsessy $v$ Baikal'skoi riftovoi zone [Seismoionospheric and Seismoelectromagnetic Processes in the Baikal Rift Zone]. Novosibirsk, SB RAS Publ., 2012, pp. 74-76. (In Russian).

Antonova V.A., Gurevich A.V., Zybin K.P., Karashtin A.N., Kryukov S.V., Ryabov V.A., Ptitsyn M.O., Chubenko A.L., Shlyugaev Yu.V., Shchepotov A.L. Atmospheric electric field effect on cosmic ray registration by neutron monitor. Izvestiya NAN RK. Seriya fiziko-matematicheskaya [News of NAS RK. Physico-Mathematical Series]. Almaty, 2008, no. 4, pp. 11-15. (In Russian).

Babich L.P., Bochkov E.I., Dwyer J.R., Kutsyk I.M., Zalyalov A.A. Numerical analysis of 2010 high-mountain (TienShan) experiment on observations of thunderstorm-related lowenergy neutron emissions. J. Geophys. Res.: Space Phys. 2013, 
vol. 118, pp. 7905-7912. DOI: 10.1002/2013JA019261.

Babich L.P., Bochkov E.I., Zalyalov A.A., Kutsyk I.M. On amplifications of photonuclear neutron flux in thunderstorm atmosphere and possibility of detecting them. JETP Letters. 2013, vol. 97, iss. 6, pp. 291-296. DOI: 10.1134/ S0021364013060027.

Chilingaryan A. Are relativistic elementary particles born in thunderstorm discharges? Izvestiya RAN. Seriya fizicheskaya [Bulletin of the Russian Academy of Sciences: Physics]. 2017. vol. 81, no. 2, pp. 258-261. DOI: 10.7868/ S0367676517020144. (In Russian).

Enoto T., Wada Y., Furuta Y., Nakazawa K., Yuasa T., Okuda K., Makishima K., Sato M., Sato Y., Nakano T., Umemoto D., Tsuchiya H. Photonuclear reactions triggered by lightning discharge. Nature. 2017, vol. 551, pp. 481-484 DOI: 10.1038/nature24630.

Kozlov S.A., Yanchukovsky A.L. Usilitel'-diskriminator $k$ neitronnomu monitoru NM-64 i kontrol' raboty detektora [Amplifier-Discriminator for the Neutron Monitor NM-64 and Detector Control]: Preprint SibIZMIR no. I7-87. Irkutsk, 1987, 13 p. (In Russian).

Makhmutov V.S., Stozhkov Y.I., Philippov M.V., Bazilevskaya G.A., Kvashnin A.N., Viktorov S.V., Panov V.M., Raulin J.-P., Tacza J., Marun A., Fernandez G. Variations in cosmic rays and the surface electric field in January 2016. Bulletin of the Russian Academy of Sciences: Physics. 2017, vol. 81, no. 2, pp. 241-244. DOI: 10.3103/S1062873817020265.
Shah G.N., Razdan H., Bhat G.L., Ali G.M. Neutron generation in ligtnings bolts. Nature. 1985, vol. 313, pp. 733-755.

Starodubtsev S.A., Kozlov V.I., Toropov A.A., Mullayarov V.A., Grigor'ev V.G., Moiseev A.V. First experimental observations of neutron bursts under thunderstorm clouds near sea level. JETP Letters. 2012, vol. 96, iss. 3, pp. 188-191. DOI: 10.1134/S0021364012150106.

Yanchukovsky A.L., Kozlov S.A. AIIS - novyi komponent Sayanskogo spektrografa kosmicheskikh luchei [AIIS a New Component of the Sayan Cosmic Ray Spectrograpl Preprint SibIZMIR no. I8-88. Irkutsk, 1988, 35 p. (In Russian).

URL: http://ckp-rf.ru/ckp/3056 (accessed March 20, 2019)

Color images are available in the electronic version of the article.

How to cite this article

Lukovnikova A.A., Aleshkov V.M., Lysak A.S. Observing the neutron component during thunderstorm activity at a mountain CR station. Solar-Terrestrial Physics. 2019. Vol. 5. Iss. 3. P. 54-58. DOI: $10.12737 /$ stp-53201906. 